\title{
The Rock Church of San Micidiario of the Pantalica Site and 3DLAB VR/AR-Project
}

\author{
Giuseppe Di Gregorio
}

Abstract

This work gives the first results of a research project funded by the Sicily region, aimed at the creation of virtual reality (VR), augmented reality (AR) models, in the context of some country of the territory of Sicily with UNESCO listed monuments. This project sees the collaboration between some universities on the island and some partners who produce software and automated robotics systems and Al. Below are the first results of the workflow produced for the creation of 3D models of one of the three rock churches of the necropolis of Pantalica: an Unesco site. It also describes the process underway to get to the creation of $V R$ and $A R$ models to be used with three different levels of immersive reality: normal commercial viewers, different types of Oculus viewers, or in special virtual rooms Cave Automatic Virtual Environment (CAVE), already existing or created within the project.

Keywords

3D survey, digital survey, SFM, photogrammetry, VR/AR.

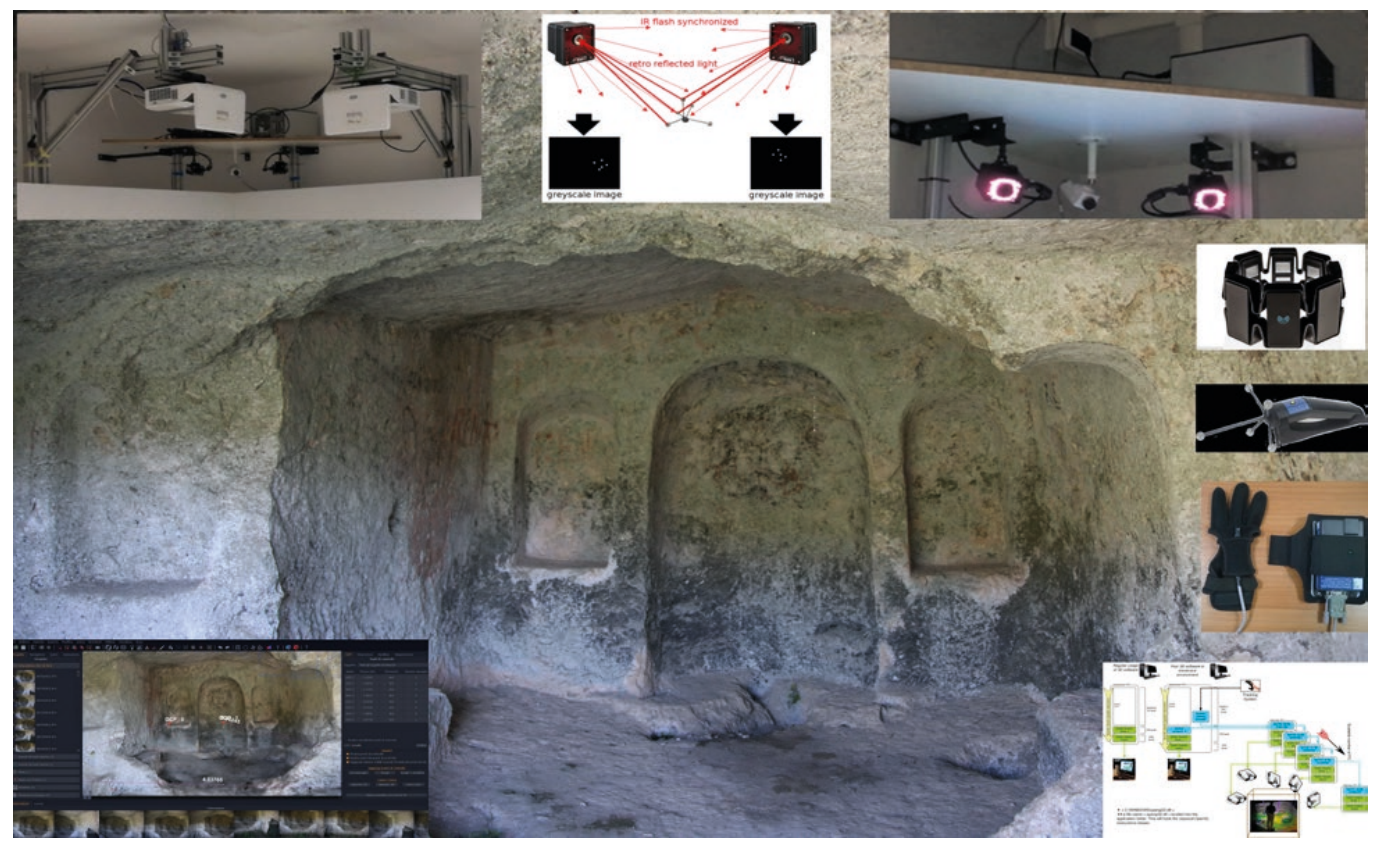




\section{Introduction}

The ever-increasing and increasingly cheaper availability of active and passive sensors, such as 3D laser scanners and sophisticated photogrammetry systems, with increasingly versatile and feature-rich software environments, on the one hand, and fixed equipment on the other with wearable devices for the use of highly immersive environments has made it possible to create a real market of Virtual Reality (VR) and Augmented Reality (AR) which, according to the Worldwide Semiannual Augmented and Virtual Reality Spending Guide by IDC, has accelerated over the last five years, with a compound annual growth rate of 198\%, to the point of reaching $\$$ I 43.3 billion in 20 I 8.VR applications are increasingly widespread and numerous in many fields, such as: medicine, biology, automotive , manufacturing, cultural heritage, public administration, "internet of things", architecture, gaming, advertising, online sales, communication and marketing, tourism, and publishing, fashion, education, training, etc. and the emerging integration of $\mathrm{VR}$ into business processes such as design, production, simulation, maintenance, safety, etc. is extremely significant. It is therefore no wonder that advanced visualization VR/AR laboratories are in continuous creation and development, both in an academic and industrial environment, often with public-private co-management and that in 2017 the European Commission funded the VISIONAIR project, which had the goal, successfully achieved, to create a continental network with more than $20 \mathrm{VR}$ and $3 \mathrm{D}$ visualization centers and to validate it with about 200 applications and projects of cultural heritage, biology, chemistry, engineering, mechatronics, medicine, and much more, selected through competitive procedures.

\section{The 3DLAB Sicily Project}

As part of a project funded by the Sicily region, the Department of Civil Engineering and Architecture of the University of Catania (DICAR) participates in the development of VR and AR models, through a research group related to the disciplines of design and representation, which intervenes for some Cultural Heritage, in the context of various municipalities already registered as UNESCO sites. Among these it is worth mentioning the country of Sortino (SR) with the important and vast archaeological site of the necropolis of Pantalica. Among the various purposes: - improve and enhance the use and enhancement of the artistic, cultural and environmental resources of the territory, given that virtual reality environments are becoming one of the impulses of tourism 4.0., - use technologies to create applications that allow an extremely dynamic and multisensory interaction of the island's cultural heritage, - create, develop, validate and promote a sustainable regional network of some centers for VR/AR and 3D visualization, - federate the infrastructure with that of VISIONAIR, in order to create visibility at an international level; - create a service that borrows the concept of "liquid lab" or "liquid studio".

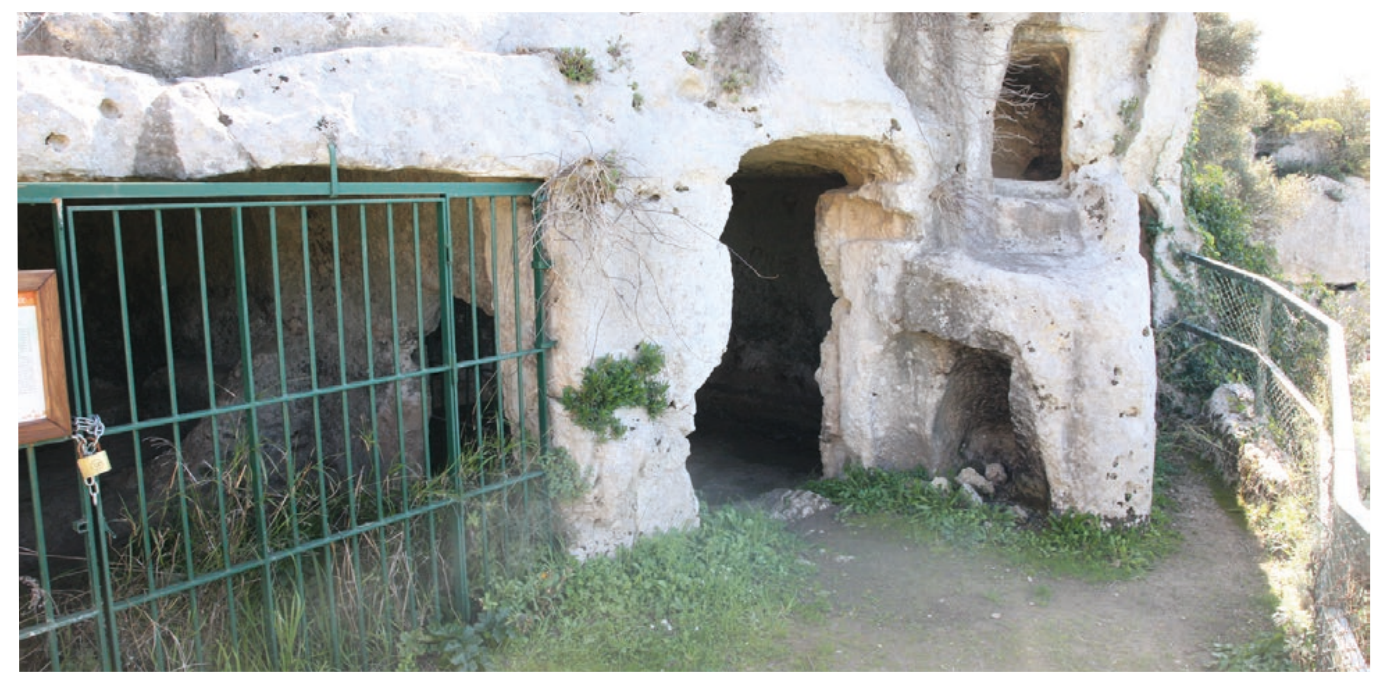




\section{The Rock Churches of Pantalica}

Declared a UNESCO site in 2005, the site of Pantalica consists of the Anaktoron or prince's palace dating back to the protohistoric period, the remains of an inhabited area of the same period, about 5,000 tombs in grotticella and the remains of three Byzantine villages linked to three rock churches also called oratories. The entire site is marked by the path of two rivers, the Calcinara and the Anapo and consists of different areas defined with different toponyms. The three rock churches are those of San Micidiario, of the Crocifisso and of San Nicolicchio, located on three different sides, each serving a surrounding village. Paolo Orsi identified for these oratories a high medieval rock settlement, expression of a natural Byzantine fortress. Furthermore, the same archaeologist placed the chronology of the three churches prior to 878 [I]. Aldo Messina in updating the catalog of the rupestrian churches of Syracuse, corrected the dating by proposing to place them in the context of the Norman period. The first rock church on which attention was paid within the 3DLAB project was that of San Micidiario (fig. I), located on the edge of a large rock village located near the saddle of Filiporto: a fortified trench. Three distinct rooms (fig. 2), communicating with each other, are part of this oratory, of which only the first two with an access from the outside. The first room is the one intended for worship and consists of a hall and a presbytery, the hall has a regular shape of about $4.00 \times 2.70 \mathrm{~m}$, while the presbytery has dimensions of about $\mathrm{m} 2.70 \times 2.00 \mathrm{~m}$, while the presbytery has dimensions of about $\mathrm{m} 2.70 \times 2.00$ and occurs at a greater share of the room that precedes it, the other two rooms with an almost regular plan, have dimensions of about $\mathrm{m} 3.90 \times 3.80$ and $2.65 \times 4.24 \mathrm{~m}$. In the cult environment, in the area that separates the two zone, the attacks of the rock of a pre-existing templon are still visible, which would strengthen the Byzantine origin with three openings that repeated the geometry of the apse area. Orsi tells us that he found a painted plaster in the apse area, of which only traces are visible today. The information that a poly-figurative composition existed in the apse area remains confirmed, the issue was dealt with and deepened by G. Arcidiacono [2].

\section{The Creation of the 3D Model and VR/AR}

The first phase of processing involved the use of SfM, the equipment used is a Canon full frame digital camera. To create the 3D model, the multi-image photogrammetry application SfM Zephyr by 3DFLOW was used (fig. 3). The result was a unique 3D model for the three environments, with the ability to navigate continuously within the three volumes. After checking other aspects, several elaborations followed, including the section with a horizontal plane to obtain a section in 3D. This acquisition and processing through multi-image photogrammetry is accompanied by a scan with the Faro 350 plus Laser Scanner, in order to evaluate the results for the definition quality of the rock walls, for the creation of the VR model between the two systems. The 3Dlab project involves the use of three VR CAVES. The first VR CAVE already operational, was developed by SWING:IT [3], and is used for production of applications, as part of research and development projects and for services to

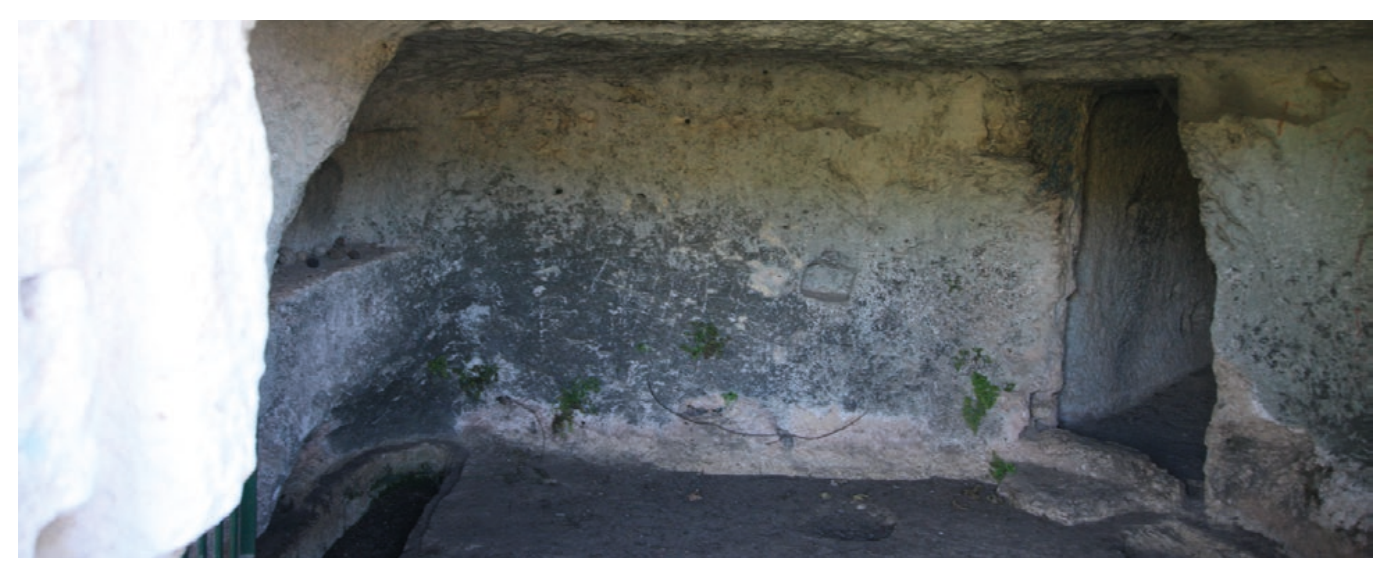


Fig. 3. Pantalica

San Micidiario the

presbytery zone, Zephyr
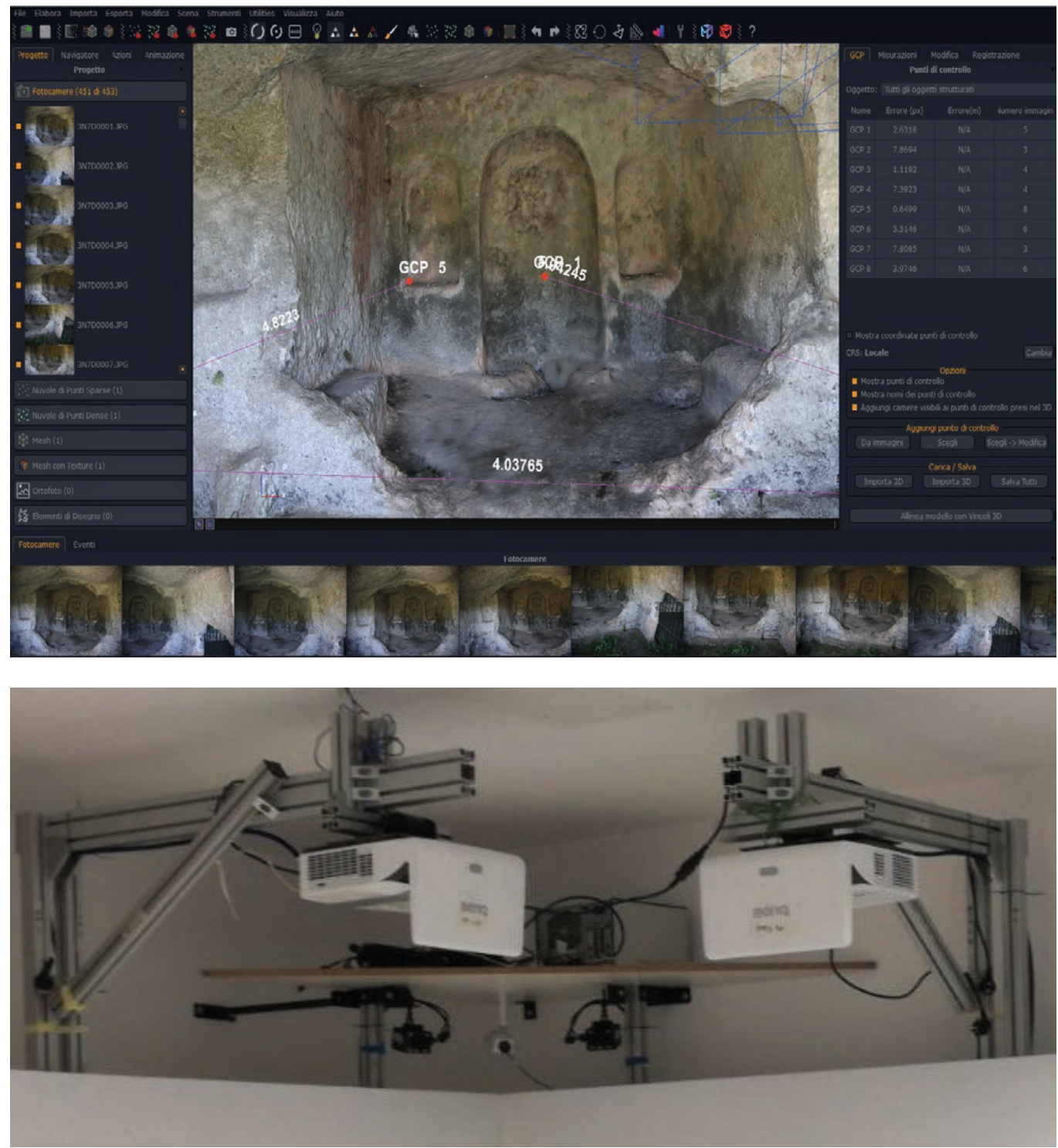

Server

Arduino

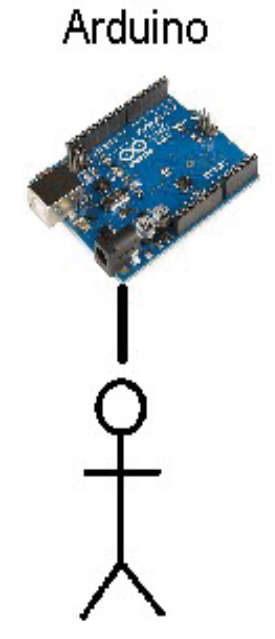

Utente

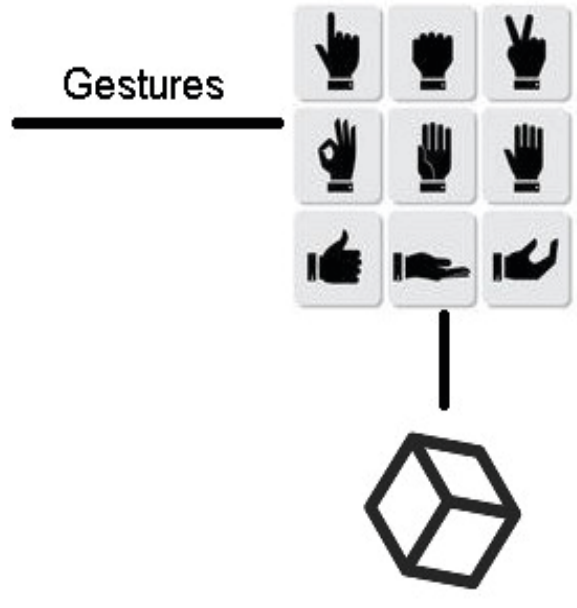

Applicazione 
third-party activities that require an advanced visualization infrastructure.The Virtual Room is a structure capable of reproducing an immersive virtual reality experience IVR (Immersive Virtual Reality), organized on a video-theater inside which images are projected using 3D projectors (fig.4) and/or screens, together with appropriate 3D software. One of the strengths of the SWING:IT system is the presence of the tracking sub-system, which allows you to track the user's position, using this information for real-time recalculation of the perspective vision, thus giving the user the sensation of navigation within the 3D scene. The SWING: IT virtual room is controlled by two PC, the rendering node (Render PC), dedicated exclusively to scene rendering and the processing node (Master PC), which takes care of the software execution.Video projectors take care of projecting 3D images on the panels, with a projector for each panel. The tracking system adopted is the ARTTRACK5, a stand-alone system, which uses an infrared (IR) tracking method, equipped with a central unit that holds the tracking logic to which the infrared cameras refer. Finally, a "Pattern Recognition" system is able to determine the position and orientation of each individual marker present within the tracking area, using the Hand Track and Crystal Eyes as input peripherals. Therefore, additional input devices are being evaluated to be integrated and tested to improve the immersive experience within the Virtual Room, while avoiding introducing additional disturbing elements to users. As part of the development of the project 3DLAB, SWING:IT is evaluating the possibility of expanding the list of input devices in order to improve the immersive experience (fig. 5). The 3D scenes are created through the Unity 3D development platform, the application generated produces a video output that is managed by the Tech $V i z X L$ software, which is able to view the $3 D$ scenes without any limitation of resolution and performance.

\section{Acknowledgements}

This work, equipment illustrated were supported by the project "Creazione di una rete regionale per l'erogazione di servizi innovativi basati su tecnologie avanzate di visualizzazione" (3DLab-Sicilia), Grant No. 08CT4669990220, funded by Operational Program 2014-2020 of the European Regional Development Fund (ERDF) of the Sicilian Region.

\section{Notes}

[I] Arcdiacono G., 2019, Le ultime fasi di Pantalica: le chiese rupestri e la loro decorazione pittorica, sta in Atti del convegno di Sortino (SR) 15-16 dicembre 2017, Consorzio Universitario Archimede Soprintendenza BB.CC.AA. - Siracusa, Scuola di specializzazione in Beni Archeologici - UNICT, Comune di Sortino, Bottega D'Erasmo Aldo Ausilio Editore in Padova, p.204.

[2] Arcidiacono G., 2019, pp. 203-221

[3] SWING IT is the acronym or abbreviation of Software Engineering based in San Giovanni La Punta (CT), and is one of the partners of the 3DLAB SICILY project.

\section{References}

Blancato Mario, Militello Pietro, Palermo Dario, Panvini Rosalba (eds.) (2019). Pantalica e la Sicilia nelle età di Pantalica. Padova: Bottega D'Erasmo.

Jerald Jason (2015). The VR Book: Human-Centered Design for Virtual Reality. ACM Books.

Montagna Lorenzo (20 18). Realtà virtuale e realtà aumentata. Nuovi media per nuovi scenari di business. Milano: Hoepli.

Orsi Paolo ( 1 898). Chiese bizantine nel territorio di Siracusa. In Byzantinische Zeitschrift, VII, pp. I-28

Orsi Paolo (1910). Byzantina Siciliae I. II tesoro bizantino di Pantalica. In Byzantinische Zeitschrift, XIX, pp. 63-90, pp. 462-475.

\section{Author}

Giuseppe Di Gregorio, Dept. of Civil Engineering and Architecture, University of Catania, giuseppe.digregorio@unict.it 
